\title{
Acquired Cutis Laxa
}

\section{Edinsel Kutis Laksa}

(D) Ankur Jain

Vardhman Mahavir Medical College and Safdarjung Hospital, Department of Hematology, New Delhi, India

To the Editor,

The term monoclonal gammopathy of renal significance (MGRS) refers to paraprotein-mediated renal injury associated with an underlying clonal lymphoproliferative disorder, not meeting the criteria for multiple myeloma, Waldenstrom macroglobulinemia, or systemic lymphoma requiring therapy. Clone size (B-cell, plasma cell, or lymphoplasmacytic cell) and the resultant paraprotein are frequently small, and renal impairment results from unique physicochemical properties of the paraprotein rather than the tumor burden per se [1]. Heavy chain deposition disease (HCDD) is one of the rarest MGRS entities. Since its first description in 1993, fewer than 100 cases have been described so far $[2,3,4]$. HCDD results from tissue deposition of the truncated monoclonal non-amyloidogenic heavy chain $(\mathrm{HC})$ with deleted constant region ( $\mathrm{CH} 1)$, most commonly $\lg \mathrm{G}$ $(\gamma-\mathrm{HCDD}, \lg \mathrm{G} 1>\lg \mathrm{G} 3)[1,2]$. Deletion of the constant region (CH1) facilitates the extracellular secretion and tissue tropism of the $\mathrm{HC}$, culminating in complement-mediated end organ damage [2]. Kidneys are the most commonly affected organs, followed by skin, cardiopulmonary, gastrointestinal, vesicourinary, and musculoskeletal systems [4]. Renal involvement frequently manifests with nephrotic-range proteinuria, hematuria, hypertension, progressive renal insufficiency, and hypocomplementemia [2,3]. Acquired cutis laxa (ACL) refers to loosening of skin due to elastotic degeneration of the dermis. Although generally associated with inflammatory conditions, a few cases of ACL have been described in association with $\gamma$-HCDD. $\gamma$-HCDD-associated ACL results from monoclonal IgG-HC dermal deposition and complement-mediated elastin degeneration $[4,5]$.

A 34-year-old Indian male developed loosening of the skin of the face, neck, and bilateral axillary folds in 2016 (Figure 1). Skin biopsy revealed loss of elastic fibers in the upper dermis, consistent with cutis laxa (CL). The patient complained of frothy urine and bilateral leg edema in 2019. A nephrology review suggested hypertension, renal insufficiency (estimated glomerular filtration rate: $15 \mathrm{~mL} / \mathrm{min} / 1.73 \mathrm{~m}^{2}$ ), inactive urine sediment, and nephrotic-range proteinuria. Kidney biopsy revealed glomerular enlargement, lobular mesangial matrix expansion with nodularity, and glomerular basement membrane splitting (silver methenamine stain). Immunohistochemistry showed linear IgG deposition along the glomerular basement membrane (immunonegative for kappa and lambda), which appeared 'powdery' dense on electron microscopy, confirming the diagnosis of $\gamma$-HCDD. Bone marrow aspirate showed $5 \%$ clonal plasma cells. Serum immunofixation identified an lgGlambda monoclonal spike, and the serum free light chain ratio (sFLCr) was 0.1 (reference range: 0.26-1.65). Serum complement levels were normal and cryoglobulins were negative. The patient became dialysis-dependent and succumbed to progressive renal failure after 2 cycles of cyclophosphamide, bortezomib, and dexamethasone chemotherapy.

Due to small-sized paraprotein, about one-third of cases of $\gamma$-HCDD do not have a measurable monoclonal spike on conventional serum electrophoresis. Since clonal cells secrete monoclonal light chains in addition to the pathogenic $\mathrm{HC}$, the sFLCr is frequently abnormal and could help in the diagnosis and response evaluation of $\gamma$-HCDD [2]. The renal prognosis of $\gamma$-HCDD is poor. However, clone-directed therapy, and particularly bortezomib-based therapy (with/without autologous stem cell transplantation) for associated plasma cell dyscrasia, was shown to improve renal outcomes $[1,2,3]$. ACL is a rare dermatological manifestation of $\gamma$-HCDD. Its presentation can precede the renal involvement by many years [5]. The current report highlights the need to meticulously search for monoclonal protein and its implicated clone in patients presenting with features of ACL. Early recognition and timely initiation of clone-directed therapy may improve renal outcomes.

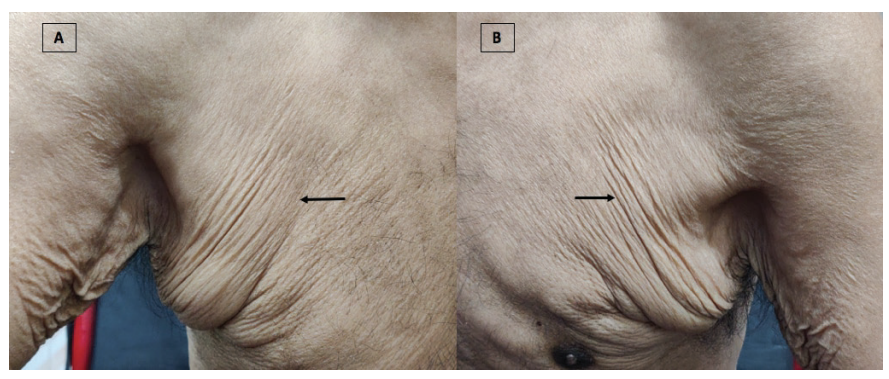

Figure 1. Clinical photograph of the patient showing loosening of folds of bilateral axillae (A and B). Skin biopsy findings were consistent with the diagnosis of acquired cutis laxa. 
Keywords: Cutis laxa, Monoclonal gammopathy of renal significance, Chemotherapy

Anahtar Sözcükler: Kutis Laksa, Renalin monoklonal gammopatisi önem, Kemoterapi

Informed Consent: The author declares that consent was obtained from the patient prior to publication of any material.

Financial Disclosure: The author declared that this study received no financial support.

\section{References}

1. Jain A, Haynes R, Kothari J, Khera A, Soares M, Ramasamy K. Pathophysiology and management of monoclonal gammopathy of renal significance. Blood Adv 2019;3:2409-2423.
2. Bridoux $F$, Javaugue $V$, Bender $S$, Leroy $F$, Aucouturier $P$, Debiais-Delpech $C$, Goujon JM, Quellard N, Bonaud A, Clavel M, Trouillas P, Di Meo F, Gombert $J M$, Fermand JP, Jaccard A, Cogné M, Touchard G, Sirac C. Unravelling the immunopathological mechanisms of heavy chain deposition disease with implications for clinical management. Kidney Int 2017;9:423-434.

3. Zhang $Y$, Li $X$, Liang $D, X u F$, Liang $S$, Zhu $X$, Zheng $N$, Huang $X$, Liu Z, Zeng C. Heavy chain deposition disease: clinicopathologic characteristics of a Chinese case series. Am J Kidney Dis 2020;75:736-743.

4. Majithia RA, George L, Thomas M, Fouzia NA. Acquired cutis laxa associated with light and heavy chain deposition disease. Indian Dermatol Online J 2018:9:44-46.

5. Kim DP, Klein PA. Acquired cutis laxa in a 55-year-old female with multiple myeloma and serologic evidence of systemic lupus erythematosus. Dermatol Online J 2011:17:8.

\title{
Recurrent Pregnancy-Related Pure Red Cell Aplasia Responsive to Combined Corticosteroid and Azathioprine Therapy: A Management Dilemma
}

\author{
Kortikosteroid ve Azatioprin Kombine Tedavisine Yanıt Veren Tekrarlayan Gebelik-Ilişkili Saf \\ Kırmızı Hücre Aplazisi: Bir Yönetim Ikilemi
}

(D) Ashwin Rao, (D) Rashmi Rao

Salem Polyclinic, Department of Obstetrics and Gynecology, Tamil Nadu, India

To the Editor,

Pure red cell aplasia (PRCA) is associated with normocytic normochromic anemia, severe reticulocytopenia, and reduced erythroid precursors in the bone marrow [1]. PRCA may be congenital or acquired. Among the acquired cases, pregnancy has been associated with PRCA [2].

A 25-year-old primigravid patient presented at 10 weeks of gestation with severe anemia with breathlessness for 2 months with no history of fever, jaundice, or weight loss. On examination, she had pallor but no icterus, peripheral lymphadenopathy, or hepatosplenomegaly. Laboratory investigations showed a hemoglobin level of $5.5 \mathrm{~g} / \mathrm{dL}$, red blood cell (RBC) count of 1.53 million $/ \mathrm{mm}^{3}$, and white blood cell (WBC) count of $5280 / \mu \mathrm{L}$.
Her mean corpuscular volume, mean corpuscular hemoglobin, and mean corpuscular hemoglobin concentration were $81.2 \mathrm{fL}$, $25.8 \mathrm{pg}$, and $31.8 \mathrm{~g} / \mathrm{dL}$, respectively. A peripheral smear showed normocytic normochromic RBCs with occasional spherocytes with reticulocytes of $0.3 \%$. Hence, the absolute reticulocyte count was $200 / \mu \mathrm{L}$ and the reticulocyte index was 0.15 , which was suggestive of hypoproliferation. Ultrasound showed a single live intrauterine pregnancy corresponding to 9 weeks. On admission, packed RBCs were transfused. Hemoglobin electrophoresis was performed, which ruled out thalassemia. Other investigations for liver, renal, and endocrine functions were normal. Bone marrow aspirate cytology (Figure 1) showed occasional basophilic erythroblasts and promegaloblasts with moderate lymphocytosis. The percentage of erythroid precursors was $0.8 \%$ 